\title{
Boron Hyperaccumulation Mechanisms in Puccinellia distans as Revealed by Transcriptomic Analysis
}

Saniye Elvan Öztürk ${ }^{1}$, Mehmet Göktay, ${ }^{1}$ Canan Has ${ }^{1}$, Mehmet Babaoğlu ${ }^{2}$, Jens Allmer ${ }^{1}$, Sami Doğanlar $^{1}$, Anne Frary ${ }^{1 *}$

${ }^{1}$ Department of Molecular Biology and Genetics, Izmir Institute of Technology, Urla, Izmir 35430, Turkey

${ }^{2}$ Department of Field Crops, Selcuk University, Selçuklu, Konya, 42030, Turkey

*Corresponding author: annefrary@iyte.edu.tr

\section{Author contribution statement}

SEO performed laboratory experiments; $\mathrm{MG}$ and $\mathrm{CH}$ performed bioinformatics analysis; $\mathrm{MB}$ provided plant materials; SD, JA and AF designed the study; SEO, CH, JA and AF drafted and revised the manuscript. All authors read the manuscript and agreed upon the final version of the manuscript. 


\begin{abstract}
Boron is an essential plant micronutrient; but is toxic at high concentrations. Boron toxicity can severely affect crop productivity in arid and semi-arid environments. Puccinellia distans (Jacq.) Parl., common alkali grass, is found throughout the world and can survive under boron concentrations that are lethal for other plant species. In addition, $P$. distans can accumulate very high levels of this element. Despite these interesting features, very little research has been performed to elucidate the boron tolerance mechanism in this species. In this study, $P$. distans samples were analyzed by RNA sequencing to identify genes related to boron tolerance and hyperaccumulation. Abundance levels of selected differentially expressed transcripts were validated by real-time PCR. The results indicated that the hyperaccumulation mechanism of $P$. distans involves many transcriptomic changes including those that lead to: alterations in the malate pathway, changes in cell wall components that allow sequestration of excess boron without toxic effects, and increased expression of at least one putative boron transporter and two putative aquaporins. Elucidation of the boron accumulation mechanism is important to develop approaches for bioremediation of boron contaminated soils.
\end{abstract}

Key words: Bioremediation, boron, ESTs, hyperaccumulation, Puccinellia distans (Jacq.) Parl., RNA sequencing, toxicity 


\section{INTRODUCTION}

Boron (B) is a plant micronutrient and is essential for plant cell wall formation (Marschner \& Marschner, 2012). Boron plays roles in many physiological and biochemical pathways for example in growth and development, including metabolism of nucleic acids, carbohydrates, proteins and indole acetic acid. Cell wall synthesis and structure (Matoh, 2001) as well as membrane integrity and function are further aspects boron is associated with (Goldbach et al., 2001; Goldbach H. E, 1997; Marschner, 2011). Soil boron concentrations vary from deficient to toxic in different regions of the world (Yau et al., 1995). The majority of soil boron is found in Turkey (72.5 \% of world reserves), followed by Russia, USA, and China (BOREN, 2012). Important boron reserves are located in the northwest part of Turkey in Balikesir, Bursa, Kutahya and Eskisehir provinces (Ozturk et al., 2010). Boron levels are also affected by rainfall and boron-rich groundwater which can cause boron toxicity in arid and semi-arid regions of the eastern Mediterranean, western Asia/north Africa, the Indian subcontinent, China, Japan and South America (Nable et al., 1997; Tanaka and Fujiwara, 2008; Sang et al., 2015).

The levels of boron that cause deficiency and toxicity vary among plants. However, in general, the difference between boron deficiency and toxicity is observed within a very narrow range. Soil boron concentrations less than $0.5 \mathrm{mg} \mathrm{kg}^{-1}$ are associated with deficiency while levels greater than $5.0 \mathrm{mg} \mathrm{kg}^{-1}$ cause toxicity (Ryan and Rashid, 2006). The tipping point between deficiency and toxicity is even finer when internal boron concentration is considered. For example, soybean leaf elongation was optimal at 10 to $12 \mathrm{mg} \mathrm{kg}^{-1}$ dry weight and impaired at both higher and lower concentrations (Kirk and Loneragan, 1988). Boron deficiency has damaging effects on many biological processes such as carbohydrate metabolism, legume nitrogen fixation (Yamagishi and Yamamoto, 1994), plasma membrane structure and cell wall integrity (Camacho-Cristóbal et al., 2008). Boron toxicity causes decreases in crop growth and productivity (Ozturk et al., 2010; Yau et al., 1995). Boron toxicity also disrupts metabolism by altering cell division and development as well as reducing cell growth. Symptoms of boron toxicity are typically observed on mature leaf margins which become chlorotic and/or necrotic (Ozturk et al., 2010).

Although excess boron is usually toxic, some plant species can tolerate high concentrations. One such species, Puccinellia distans (weeping alkali grass) was found to be extremely tolerant to boron toxicity (Padmanabhan et al., 2012). Under hydroponic conditions, $P$. distans shoots accumulated approximately $6000 \mathrm{mg} \mathrm{kg}^{-1}$ (Bar, 2015). Recent 
work by Ramila et al. (2016) suggested that a related species, Puccinellia frigida, is also highly tolerant to boron toxicity with approximately $4000 \mathrm{mg} \mathrm{kg}^{-1}$ accumulation in shoots (Rámilaa et al., 2015; Rámila et al., 2016). As a result, Puccinellia species are considered to be important candidates for phytoremediation applications. Phytoremediation is a more practical and promising solution for reducing the boron content of arid and semi-arid soils compared to chemical, physical and biological boron-removal technologies which are expensive and impractical (Padmavathiamma and Li, 2007). Despite its potential for phytoremediation, the boron hyperaccumulation mechanism of Puccinellia has not yet been elucidated.

The first boron transport mechanism described in plants was passive transport of uncharged boric acid across the plasma membrane (Marschner and Marschner, 2012). To understand the genetic factors involved in boron transport, early studies investigated nuclear genes in bread wheat and determined that the Bol, Bo2, and $\mathrm{Bo} 3$ nuclear genes control boron tolerance (Paull et al., 1992). The BoT1 and BoT2 genes were then identified in barley (Jenkin, 1993) and durum wheat (Jamjod, 1996). Later studies indicated that these genes encode active boron transporter proteins. These findings were further supported by the fact that boron uptake was hindered by mutations in BOR transporter genes and metabolic inhibitors in species including A. thaliana (Takano et al., 2001), barley (Hayes, 2004), sunflower (Matoh and Ochiai, 2005), wheat (Reid, 2007), and rice (Uraguchi and Fujiwara, 2011). Boron uptake is also mediated by major intrinsic channel-like transporter proteins (MIPs) in sunflower (Dannel et al., 2000), squash (Dordas \& Brown, 2000), and Arabidopsis (Takano et al., 2006). Among these MIPs, a number of aquaporins are reported to be permeable to physiologically important molecules such as boron, silicon, ammonia, hydrogen peroxide, and carbon dioxide (Chaumont et al., 2005). Indeed, two aquaporins in A. thaliana were shown to have boric acid channel activity (Takano et al., 2006; Takano et al., 2008).

The main goal of this study was to examine the hyperaccumulation/tolerance mechanisms of $P$. distans under high boron conditions. To achieve this goal, we used RNA sequencing to compare the expression profiles of plants grown under control and normally toxic boron conditions. Differentially expressed transcripts were annotated at the protein level and gene ontology and pathway analyses were performed against the model organisms, $O$. sativa and A. thaliana. The differentially regulated proteins were found to be located in several areas including membrane-associated complexes, the cytosol and nucleus. These proteins play roles in several molecular pathways including carbon, energy, amino acid, and lipid metabolism; signal transduction and transport. In this way, we identified candidates 
including an A. thaliana boron transporter, an O. sativa nodulin-26 like Intrinsic Protein (NIP) and other stress response-related transcripts in $P$. distans. A greater understanding of the hyperaccumulation/tolerance mechanism(s) of the monocot $P$. distans will provide insight into ways of coping with boron stress toxicity in agriculturally important cereals such as rice, maize, and sorghum. Thus, while $P$. distans itself might be used to eliminate excess boron from soil, the tolerance mechanism(s) could be transferred to crop plants to confer boron tolerance and/or to develop a faster-growing, higher biomass phytoremediation system.

\section{MATERIALS \& METHOD}

\subsection{Plant material and boron treatment}

Seeds of $P$. distans collected from a boron mining site, Kirka-Eskisehir, Turkey $\left(39^{\circ} 17^{\prime}\right.$ 23.7156" and 30 31'33.4812") (Babao $\square$ lu et al., 2004), were germinated in potting soil. The germinated seedlings were grown for 2 weeks in a growth chamber maintained at $25 \pm 2{ }^{\circ} \mathrm{C}$, $60 \%$ relative humidity and $16 \mathrm{~h}$ photoperiod (Stiles et al., 2010). After four weeks, plants were transferred to half strength Hoagland solution (Hoagland and Arnon, 1950) and grown for one week. Plants were separated into two groups with three replicates: $0.5 \mathrm{mg} \mathrm{L}^{-1}$ boron was applied to the control group and $500 \mathrm{mg} \mathrm{L}^{-1}$ was applied to the stress group (Stiles et al., 2010). The boron concentration in Hoagland solution was adjusted with boric acid and the solution was changed once every three days for three weeks. After 3 weeks of treatment, plants were removed from the Hoagland solution and rinsed of any contamination with RNase-free water. The shoot tissues were then frozen in liquid nitrogen and stored at $-80^{\circ} \mathrm{C}$.

\subsection{RNA isolation}

Total RNA was isolated from the shoot samples using an RNeasy Plant Mini Kit (Qiagen, Maryland, USA). The quality and quantity of isolated shoot RNA from control and stress samples were measured using a Nanodrop ND-100 device (Nanodrop Technologies, Wilmington, DE, USA).

\subsection{RNA sequencing and analysis}

Extracted total RNA samples were processed using a TruSeqTM RNA Sample Preparation Kit (Illumina, Tokyo, Japan) for cDNA library construction and subsequent EST identification. ESTs were sequenced for control and stress libraries using an Illumina HighSeq 2000 platform (Takara, Tokyo, Japan) to generate 125 bp paired end (PE) reads. RNA sequencing was performed by GATCBiotech (Constance, Germany). Raw data consisted of 45 million reads for each sample with read length fixed at 125 nucleotides. 
The Cutadapt2 (version 1.9.1) program (Martin, 2011) was employed with default parameters to remove adapter sequences and low quality nucleotides from raw reads. Reference transcriptome construction was performed using the Trinity (version 2.2.0) assembly tool (PMID: 23845962) (Haas et al., 2013). All reads from the control and stress samples were treated the same. The reference transcriptome was used to map the cleaned reads from control and stress datasets individually using the Bowtie2 program (version 2.1.0) (Langmead \& Salzberg, 2012). Mapping information for each dataset was saved in a binary alignment information (bam) file. The bam files were used as inputs for differential gene expression analysis performed with the Cufflinks (version 2.2.1) pipeline (Cufflinks, Cuffmerge, and Cuffdiff) (Trapnell et al., 2012). Results were analyzed and visualized using the cummeRbund (version 2.15) R statistics package (Goff et al., 2013). Differentially expressed gene sequences were extracted based on q-value (q-value threshold $<0.05$, where $\mathrm{q}$-value is the false discovery rate adjusted p-value of the test statistic). Differentially expressed candidates were then annotated using Blast2GO (version 4.0.7) (Conesa et al., 2005) against a custom protein database which included $O$. sativa and $A$. thaliana proteins in UniProt Knowledgebase (release date: November 2016). Gene ontology analysis was carried out with QuickGO (Binns et al., 2009). Protein functional classification based on gene ontology was performed by PANTHER Protein Classification System (Accession date: November, 2016) (Mi et al., 2016). Annotated transcripts were search against the KEGG (Kyoto Encyclopedia of Genes and Genomes) database (Tanabe \& Kanehisa, 2012) to reveal the pathways in which up and down-regulated transcripts have roles.

\subsection{Evolutionary conservation}

Phylogenetic analyses of boron transporters and other ion transporters of multiple species were performed to determine their sequence similarity and evolutionary conservation. This analysis included all of the fourteen transporters found to be up or down-regulated by boron stress in this work: O. sativa boron NIP transporter (UniProtID: Q949A7), A. thaliana TIP transporter (UniProtID: O82598), A. thaliana BOR6 transporter (UniProtID: Q3E954), A. thaliana sugar transporters (UniProtIDs: Q4F7G0, O04249), O. sativa sulfate transporter (UniProtID: Q8S317), O. sativa anion transporter (UniProtID: Q652N5), A. thaliana inorganic phosphate transporter (UniProtID: Q38954), and A. thaliana ABC transporters (UniProtIDs: Q9C9W0, Q8LPJ4, Q7GB25, Q9FWX7, Q9FJH6, Q9M1H3). In addition, 11 boron transporters described in the literature were used in the analysis including those from $O$. sativa (UniProtIDs: Q1ZYR7, Q7X9F3), A. thaliana (UniprotID: Q8VYR7, Q9XI23, Q93Z13, Q9M1P7, Q9SUU1, Q9SSG5), Hordeum vulgare (UniProtID: M0Z9M9), Brassica 
napus (UniProtID: D5LGA1, D5LG97). Two A. thaliana NIP transporters (UniProtID: Q9SV84, Q9SAI4) were also included. Sequences for these proteins were retrieved from the UniProtKB database. A. thaliana nuclear transport factor 2 (NTF2) protein (UniprotID: F4J8X6) was included as outgroup. Multiple sequence alignment was conducted with the default settings of ClustalW (Larkin et al., 2007). All positions with continuous alignment gaps were eliminated using the MEGA 7.0 suite (Tamura et al., 2013). Phylogenetic tree construction was performed using the maximum likelihood method based on the Le Gascuel substitution model (Le \& Gascuel, 2008). The Gamma distribution was used to model evolutionary rate differences among sites (with default parameters except for $\mathrm{G}$ which was set to 13,3340$)$. Bootstrap values were inferred from 1000 replicates. In order to compute phylogenetic distances, the boron and other transporters were separated into two groups. Within and between groups distances were calculated by computing the number of amino acid differences per site, averaged over all sequence pairs.

\subsection{Quantitative real-time PCR}

The expression of 30 genes that responded to boron stress in $P$. distans shoots was confirmed by qRT-PCR (quantitative real-time polymerase chain reactin) analysis using three technical replicates from one of the three biological replicates used for RNA-seq analysis. The extracted total RNA was treated with DNase I (Takara, Shiga, Japan). GoTaq ${ }^{\circledR}$ 2-Step RTqPCR kit (PROMEGA) was used for cDNA synthesis and the resulting cDNAs were amplified in the LightCycler ${ }^{\circledR} 480$ system (Roche, Basel, Switzerland) using transcriptspecific primers (Suppl. Table 1). The 30 transcripts were selected randomly from the top 50 up and down-regulated transcripts. In addition, primers were used for one known $\mathrm{ABC}$ transporter and one known boron transporter (Padmanabhan et al., 2012).

\section{RESULTS}

\subsection{Analysis of the $P$. distans transcriptome with RNA-seq}

To investigate the transcriptomic response of $P$. distans to boron stress, four cDNA libraries were generated from two replicate mRNA samples from boron-treated and control shoot samples. These libraries were sequenced using Illumina deep-sequencing HiSeq ${ }^{\mathrm{TM}}$ 2000. Raw reads of control $(90,514,028)$ and boron-treated stress $(89,278,454)$ samples were generated. Raw reads were cleaned of adapter sequences using the Cutadapt2 tool resulting in $88,663,592(98.0 \%)$ and 82,494,636 (92.4 \%) reads for control and stress samples, respectively.

The cleaned reads from the two samples were treated as input for the Trinity assembler. All reads were mapped to the constructed reference transcriptome individually 
using the Bowtie2 program. Mapping ratios for control and stress samples were $97.8 \%$ and $97.3 \%$ of cleaned reads, respectively.

Table 1: Summary of transcripts/genes statistics of $P$. distans

\begin{tabular}{ll}
\hline Parameter & \\
\hline Number of Reads (Control + Stress) & $179,792,482$ \\
Average Raw Read Length (Control + Stress) & $125 \mathrm{nt}$ \\
Average Contig Length & $496.73 \mathrm{nt}$ \\
Median Contig Length & $317 \mathrm{nt}$ \\
N50 & $609 \mathrm{nt}$ \\
Total Assembly Size & $284,371,845 \mathrm{nt}$ \\
\hline
\end{tabular}

Based on transcripts that mapped to the reference transcriptome, 284,371,845 bases were assembled from 179,792,482 reads (control + stress) (Table 1). Median and average contig lengths were 317 and $\sim 97 \mathrm{nt}$, respectively (Table 1). Additionally, the N50 value indicated that at least half the assembled bases were found in contigs that were at least $609 \mathrm{nt}$ long (Table 1).

\subsection{Differential gene expression between control and stress conditions}

Differentially expressed transcripts were detected using the RNA-Seq alignments and Cufflinks processing. Cuffdiff tracked the mapped reads and determined the fragments per kb per million mapped reads (FPKM) for each transcript in all samples. These FPKM values were used to detect up and down-regulated transcripts and most differential transcripts were found to be present or absent under control or stress conditions (Figure 1). A total of 2242 of 3312 differentially expressed transcripts were up-regulated (67.7 \%) while 1070 of 3312 (32.3 $\%$ ) were down-regulated (Suppl. Table 2). 


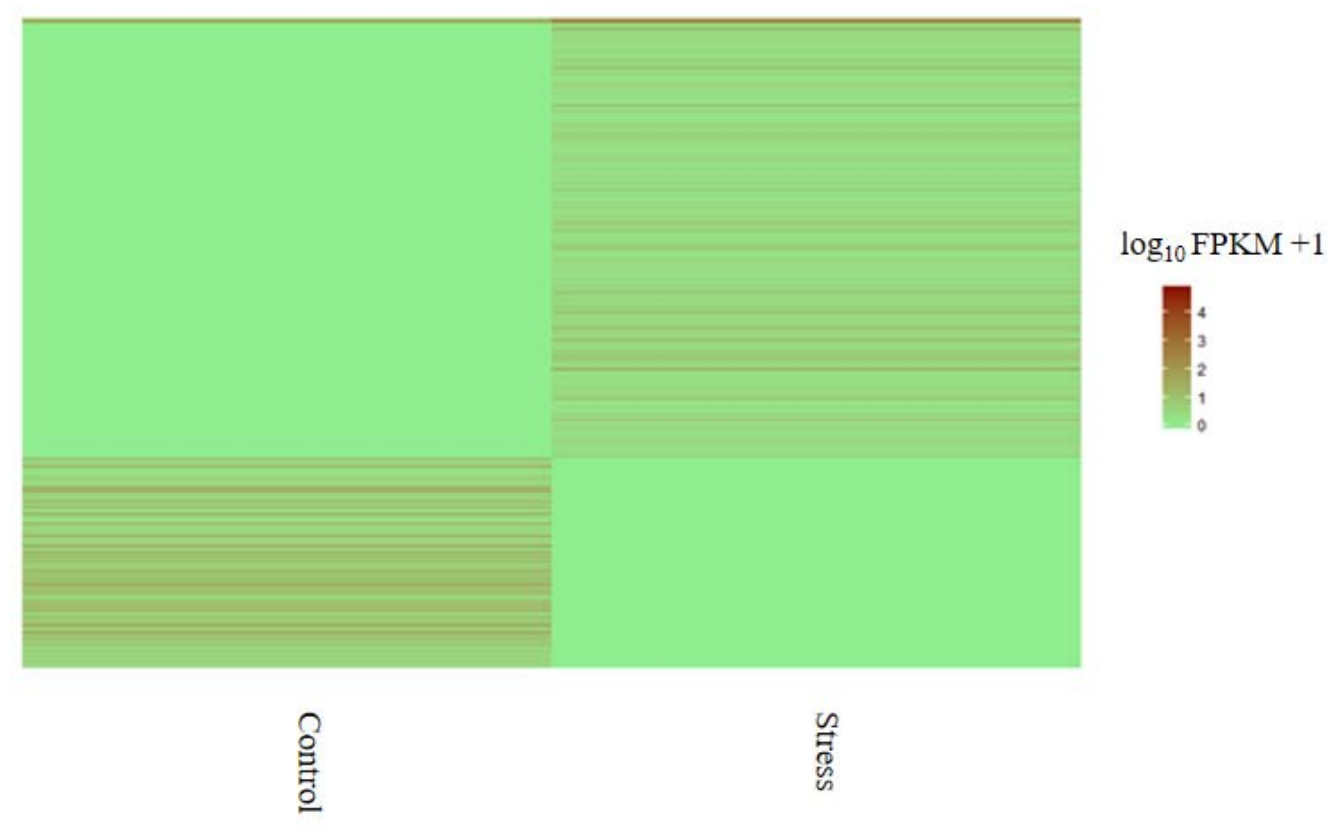

Figure 1: Heat map of log transformed FPKM values of 3312 differentially expressed transcripts from RNA-Seq of control and stress samples. FPKM ranges from 0 (green) to 5 (red).

\subsection{Annotation of differentially expressed transcripts}

The number of $P$. distans proteins and annotations available in public data repositories is limited. Therefore, $P$. distans annotation was conducted using the protein databases of two model organisms: A. thaliana and O. sativa. Both of these have extensive protein sequence resources available in the UniProt knowledgebase repository. In addition, $O$. sativa and $P$. distans belong to the same genus, Gramineae, indicating a close genetic relationship (Wang et al., 2007). 3312 transcripts were found to be differentially expressed and of these 1652 (49.9 $\%$ ) mapped to 1107 proteins. Multiple transcripts (a total of 335 transcripts) matching 36 proteins were labelled as conflicting due to matching both up and down-regulated transcripts according to their FPKM values. In order to resolve this, BLAST results were inspected manually. In this way, 36 transcripts with the highest sequence identity and best hit score were kept and the remaining transcripts were discarded as non-annotated. Among the annotated transcripts, 28 matched 21 transporter proteins (Suppl. Table 3). The annotations for the most differentially expressed transcripts (based on stress and control FPKM values) are listed in Table 2. Transcripts that did not return any match against rice and A. thaliana proteins were annotated against the green plant database (Viridiplantae). However, no additional candidate proteins were found at a significant level of match based on alignment length and E-value (data not shown). 
Table 2: Transcripts with high differential expression based on FPKM value. Annotated UniProt ID, sequence description and organism [A. thaliana (At) and $O$. sativa $(\mathrm{Os})]$ are included.

\begin{tabular}{|c|c|c|c|}
\hline UniProtID/ Annotation & Organism & Transcript Name & Difference* \\
\hline F4I600_ARATH/ V-ATPase-related & At & TRINITY_DN213899_c1_g5_i1:0-169 & 20561.12 \\
\hline H32_ARATH/ Histone & At & TRINITY_DN99923_c0_g1_i1:0-171 & 845.90 \\
\hline $\begin{array}{l}\text { RRAA2_ARATH/ 4-hydroxy-4-methyl-2- } \\
\text { oxoglutarate aldolase } 2\end{array}$ & At & TRINITY_DN220021_c1_g4_i1:0-584 & 426.28 \\
\hline $\begin{array}{l}\text { PSBR_ARATH/Photosystem II } 10 \text { kDa } \\
\text { chloroplastic }\end{array}$ & At & TRINITY_DN192927_c1_g1_i1:132-532 & 329.61 \\
\hline RD22_ARATH/ BURP domain RD22 & At & TRINITY_DN131860_c0_g2_i1:0-222 & 315.95 \\
\hline $\begin{array}{l}\text { RRAA3_ARATH/ 4-hydroxy-4-methyl-2- } \\
\text { oxoglutarate aldolase } 3\end{array}$ & At & TRINITY_DN220021_c1_g4_i2:0-391 & 299.33 \\
\hline $\begin{array}{l}\text { RRAA3_ARATH/ 4-hydroxy-4-methyl-2- } \\
\text { oxoglutarate aldolase } 3\end{array}$ & At & TRINITY_DN214561_c1_g18_i1:0-365 & 253.61 \\
\hline H2B10_ARATH/ Histone & At & TRINITY_DN199272_c0_g3_i1:2-246 & 168.98 \\
\hline H2B1_ARATH/ Histone & At & TRINITY_DN150574_c0_g1_i1:0-201 & 130.08 \\
\hline A0A160DR54_ORYSA/ Dirigent (Fragment) & Os & TRINITY_DN215985_c1_g3_i1:4-592 & 126.38 \\
\hline $\begin{array}{l}\text { RL40B_ARATH/ Ubiquitin-60S ribosomal } \\
\text { L40-2 }\end{array}$ & At & TRINITY_DN67858_c0_g1_i1:0-219 & 85.64 \\
\hline H2A1_ARATH/ Probable histone & At & TRINITY_DN28983_c0_g1_i1:38-250 & 80.83 \\
\hline $\begin{array}{l}\text { FRO7_ARATH/ Ferric reduction oxidase } \\
\text { chloroplastic }\end{array}$ & At & TRINITY_DN224067_c1_g1_i1:0-1399 & 79.87 \\
\hline H32_ARATH/ Histone & At & TRINITY_DN271392_c0_g1_i1:0-479 & 66.13 \\
\hline H2B3_ARATH/ Histone & At & TRINITY_DN199272_c0_g1_i1:0-245 & 65.63 \\
\hline H2A1_ARATH/ Probable histone & At & TRINITY_DN113560_c0_g1_i1:0-238 & 63.07 \\
\hline $\begin{array}{l}\text { XTH22_ARATH/ Xyloglucan } \\
\text { endotransglucosylase hydrolase } 22\end{array}$ & At & TRINITY_DN221642_c3_g12_i1:2-232 & 57.72 \\
\hline H32_ARATH/ Histone & At & TRINITY_DN48466_c0_g1_i1:30-384 & 51.59 \\
\hline Q01KB9_ORYSA/ Autophagy-related & Os & TRINITY_DN202627_c0_g7_i1:92-353 & 45.84 \\
\hline ACT3_ARATH/ Actin-3 & At & TRINITY_DN272586_c0_g1_i1:1-261 & 39.90 \\
\hline $\begin{array}{l}\text { SYHM_ARATH/ Histidine-tRNA chloroplastic } \\
\text { mitochondrial }\end{array}$ & At & TRINITY_DN179460_c0_g1_i1:0-227 & 39.49 \\
\hline $\begin{array}{l}\text { COX3_ARATH/ Cytochrome c oxidase subunit } \\
3\end{array}$ & At & TRINITY_DN264216_c0_g1_i1:1-257 & 38.02 \\
\hline H4_ARATH/ Histone H4 & At & TRINITY_DN8209_c0_g1_i1:0-419 & 31.53 \\
\hline Q949A7_ORYSA/ aquaporin (Fragment) & Os & TRINITY_DN210823_c0_g3_i1:4-269 & 30.12 \\
\hline H2A1_ARATH/ Probable histone & At & TRINITY_DN202443_c4_g5_i3:0-460 & 29.44 \\
\hline $\begin{array}{l}\text { FRS5_ARATH/ FAR1-RELATED } \\
\text { SEQUENCE } 5\end{array}$ & At & TRINITY_DN114402_c0_g1_i1:9-274 & 29.40 \\
\hline H2A1_ARATH/ Probable histone & At & TRINITY_DN202443_c4_g4_i2:0-314 & 25.88 \\
\hline H2A1_ARATH/ Probable histone & At & TRINITY_DN202443_c4_g4_i3:0-340 & 25.53 \\
\hline Q9LK47_ARATH/ AT3g23700 MYM9_3 & At & TRINITY_DN219995_c1_g16_i1:0-256 & 25.08 \\
\hline
\end{tabular}




\begin{tabular}{|c|c|c|c|}
\hline A0A0K0WRF9_ORYSA/ NBS-LRR type R & Os & TRINITY_DN226626_c0_g8_i1:3-253 & 24.76 \\
\hline H2A1_ARATH/ Probable histone & At & TRINITY_DN202443_c4_g1_i1:0-255 & 24.25 \\
\hline NEN3_ARATH/ NEN3 & At & TRINITY_DN226592_c4_g15_i1:8-257 & 21.50 \\
\hline RL341_ARATH/ 60S ribosomal L34-1 & At & TRINITY_DN295721_c0_g1_i1:0-414 & 20.41 \\
\hline F4HS76_ARATH/ Glycerol kinase & At & TRINITY_DN140573_c0_g2_i1:0-250 & 20.29 \\
\hline RL142_ARATH/ 60S ribosomal L14-2 & At & TRINITY_DN179003_c1_g2_i1:7-283 & 20.12 \\
\hline RL74_ARATH/ 60S ribosomal L7-4 & At & TRINITY_DN294520_c0_g1_i1:0-828 & 20.02 \\
\hline F4IJE1_ARATH/ Phox domain-containing & At & TRINITY_DN278982_c0_g1_i1:1-268 & 19.68 \\
\hline $\begin{array}{l}\text { COX2_ARATH/ Cytochrome c oxidase subunit } \\
2\end{array}$ & At & TRINITY_DN284184_c0_g1_i1:0-703 & 19.48 \\
\hline Y1457_ARATH/ Acyltransferase chloroplastic & At & TRINITY_DN222292_c3_g2_i1:0-281 & 18.69 \\
\hline Q9LTW8_ARATH/CTP synthase & At & TRINITY_DN1712_c0_g1_i1:0-285 & 18.65 \\
\hline $\begin{array}{l}\text { A0A0U2JFK9_ORYSA/ NBS-LRR-like } \\
\text { resistance }\end{array}$ & Os & TRINITY_DN213110_c2_g2_i4:22-323 & 16.98 \\
\hline UBQ3_ARATH/ Polyubiquitin 3 & At & TRINITY_DN186267_c2_g1_i1:18-638 & 16.88 \\
\hline ACT11_ARATH/ Actin-11 & At & TRINITY_DN204305_c3_g6_i2:0-375 & 16.85 \\
\hline A8MRY7_ARATH/WD-40 PCN & At & TRINITY_DN224769_c1_g7_i1:4-287 & 15.55 \\
\hline Q9STF8_ARATH/ PR-6ase inhibitor family & At & TRINITY_DN127914_c0_g2_i1:0-296 & 15.37 \\
\hline
\end{tabular}

Functional annotation was performed using Blast2GO and QuickGO based on gene ontology (GO). Cellular component, molecular function, and biological process were analyzed as GO terms for the 1107 annotated proteins. According to the ontology analysis, 906 proteins $(81.8 \%)$ were annotated to cellular components. $885(80.0 \%)$ and 848 proteins $(76.6 \%)$ were annotated with their molecular functions and biological processes, respectively.

\section{Cellular components}

Cellular component analysis lead to the annotation of 906 proteins $(81.8 \%)$ to at least one cellular component-associated term. Excess boron is trafficked from the plasma membrane to other organelles such as the vacuole and cell wall to avoid boron toxicity (Hanaoka, Uraguchi, Takano, Tanaka, \& Fujiwara, 2014) Thus, only cellular component-associated GO terms that are related to boron hyperaccumulation are presented (Suppl. Table 4). A total of $14.8 \%$ of proteins were associated with the integral component of the membrane, plasma membrane, vacuolar membrane, mitochondrial inner membrane and endoplasmic reticulum membrane. In 
addition, $1.4 \%$ of proteins were related to the cell wall, $0.8 \%$ were localized in the apoplast and $1.5 \%$ were in the vacuole.

\section{Biological processes}

Biological process annotations fell into seven main categories: response to stimulus, cellular process, metabolic process, localization, reproductive process, developmental process and signaling (Suppl. Table 5). Proteins related to the response to plant hormones and stress conditions such as salt, various ions, cold, heat, oxidative stress, and water deprivation were identified. Our findings indicated that not only translation and transcription but also protein folding and turnover; cell wall organization and biogenesis; and ion dependent redox homeostasis were regulated under excess boron. Both anabolic processes such as the malatefumarate pathway and catabolic processes such as protein and lignin pathways were altered under stress conditions. Proteins that play roles in signal transduction, in particular plant hormone-mediated and sugar-mediated signaling pathways were also differentially regulated.

\section{Molecular functions}

Molecular function annotation resulted in three main categories which contained the most transcripts: transporter activity, catalytic activity and binding (Table 3).

Table 3: Molecular function main and subcategories which were most related to boron hyperaccumulation in P. distans.

\begin{tabular}{lc}
\hline Molecular Function GOTerm & Percentage of proteins \\
\hline Binding & $39.00 \%$ \\
\hline ATP binding & $9.90 \%$ \\
Metal ion binding & $4.60 \%$ \\
RNA binding & $3.80 \%$ \\
DNA binding & $3.70 \%$ \\
Zinc ion binding & $3.20 \%$ \\
GTP binding & $1.60 \%$ \\
Translation initiation factor activity & $1.60 \%$ \\
Nucleic acid binding & $1.50 \%$ \\
Copper ion binding & $1.40 \%$ \\
Transcription factor activity, sequence-specific DNA binding & $1.10 \%$ \\
ADP binding & $1.00 \%$ \\
Heme binding & $1.00 \%$ \\
Calcium ion binding & $0.60 \%$ \\
Iron ion binding & $0.50 \%$ \\
Magnesium ion binding & $0.30 \%$ \\
HSP90 protein binding & $0.20 \%$ \\
4 iron, 4 sulfur cluster binding & $0.20 \%$ \\
Cobalt ion binding & $0.10 \%$ \\
Manganese ion binding & $0.10 \%$ \\
2 iron, 2 sulfur cluster binding & $0.10 \%$ \\
Four-way junction DNA binding & $0.10 \%$ \\
&
\end{tabular}




\begin{tabular}{|c|c|}
\hline Calmodulin binding & $0.10 \%$ \\
\hline Quinone binding & $0.10 \%$ \\
\hline Iron-sulfur cluster binding & $0.10 \%$ \\
\hline Catalytic activity & $67.00 \%$ \\
\hline Structural constituent of ribosome & $4.90 \%$ \\
\hline Protein serine/threonine kinase activity & $1.30 \%$ \\
\hline Protein kinase activity & $1.00 \%$ \\
\hline GTPase activity & $0.90 \%$ \\
\hline ATP-dependent RNA helicase activity & $0.80 \%$ \\
\hline ATPase activity & $0.80 \%$ \\
\hline NADH dehydrogenase (ubiquinone) activity & $0.60 \%$ \\
\hline $\begin{array}{l}\text { Proton-transporting ATP synthase activity, rotational } \\
\text { mechanism }\end{array}$ & $0.60 \%$ \\
\hline Structural molecule activity & $0.60 \%$ \\
\hline Oxidoreductase activity & $0.60 \%$ \\
\hline Kinase activity & $0.50 \%$ \\
\hline Signal transducer activity & $0.30 \%$ \\
\hline Peroxidase activity & $0.30 \%$ \\
\hline Metalloendopeptidase activity & $0.30 \%$ \\
\hline Cytochrome-c oxidase activity & $0.30 \%$ \\
\hline Fumarate hydratase activity & $0.20 \%$ \\
\hline Metalloaminopeptidase activity & $0.10 \%$ \\
\hline Calcium-dependent cysteine-type endopeptidase activity & $0.10 \%$ \\
\hline Glutathione transferase activity & $0.10 \%$ \\
\hline Peroxiredoxin activity & $0.10 \%$ \\
\hline $\begin{array}{l}\text { Oxidoreductase activity, acting on the } \mathrm{CH}-\mathrm{CH} \text { group of } \\
\text { donors, with a flavin as acceptor }\end{array}$ & $0.10 \%$ \\
\hline Glutathione peroxidase activity & $0.10 \%$ \\
\hline Calcium-transporting ATPase activity & $0.10 \%$ \\
\hline $\begin{array}{l}\text { Electron transporter, transferring electrons from } \mathrm{COQH} 2- \\
\text { cytochrome c reductase complex and cytochrome c oxidase } \\
\text { complex activity }\end{array}$ & $0.10 \%$ \\
\hline L-lactate dehydrogenase activity & $0.10 \%$ \\
\hline L-malate dehydrogenase activity & $0.10 \%$ \\
\hline Metallopeptidase activity & $0.10 \%$ \\
\hline Ferric-chelate reductase activity & $0.10 \%$ \\
\hline Substrate-specific transmembrane transporter activity & $0.10 \%$ \\
\hline Oxaloacetate decarboxylase activity & $0.10 \%$ \\
\hline Manganese-transporting ATPase activity & $0.10 \%$ \\
\hline $\begin{array}{l}\text { Oxidoreductase activity, acting on paired donors, with } \\
\text { incorporation or reduction of molecular oxygen }\end{array}$ & $0.10 \%$ \\
\hline Malate dehydrogenase (decarboxylating) (NADP+) activity & $0.10 \%$ \\
\hline Oxidoreductase activity, acting on the $\mathrm{CH}-\mathrm{CH}$ group of donors & $0.10 \%$ \\
\hline Oxalate decarboxylase activity & $0.10 \%$ \\
\hline $\begin{array}{l}\text { Oxidoreductase activity, acting on paired donors, with } \\
\text { oxidation of a pair of donors resulting in the reduction of } \\
\text { molecular oxygen to two molecules of water }\end{array}$ & $0.10 \%$ \\
\hline L-ascorbate peroxidase activity & $0.10 \%$ \\
\hline Cytochrome-c peroxidase activity & $0.10 \%$ \\
\hline Glutamate decarboxylase activity & $0.10 \%$ \\
\hline Myo-inositol & $0.10 \%$ \\
\hline
\end{tabular}




\begin{tabular}{|c|c|}
\hline $\begin{array}{l}\text { Oxidoreductase activity, acting on the } \mathrm{CH}-\mathrm{CH} \text { group of } \\
\text { donors, NAD or NADP as acceptor }\end{array}$ & $0.10 \%$ \\
\hline Nuclear export signal receptor activity & $0.10 \%$ \\
\hline $\begin{array}{l}\text { Oxidoreductase activity, acting on } \mathrm{NAD}(\mathrm{P}) \mathrm{H} \text {, heme protein as } \\
\text { acceptor }\end{array}$ & $0.10 \%$ \\
\hline Aspartate-tRNA ligase activity & $0.10 \%$ \\
\hline Malate dehydrogenase (decarboxylating) (NAD+) activity & $0.10 \%$ \\
\hline Oxidoreductase activity, oxidizing metal ions & $0.10 \%$ \\
\hline Protein tyrosine/serine/threonine phosphatase activity & $0.10 \%$ \\
\hline Transporter activity & $9.00 \%$ \\
\hline Transporter activity & $0.40 \%$ \\
\hline Glucose transmembrane transporter activity & $0.20 \%$ \\
\hline Sugar:proton symporter activity & $0.20 \%$ \\
\hline Inorganic phosphate transmembrane transporter activity & $0.20 \%$ \\
\hline Malate transmembrane transporter activity & $0.10 \%$ \\
\hline L-ascorbic acid transporter activity & $0.10 \%$ \\
\hline Secondary active sulfate transmembrane transporter activity & $0.10 \%$ \\
\hline Antiporter activity & $0.10 \%$ \\
\hline Voltage-gated ion channel activity & $0.10 \%$ \\
\hline Anion:anion antiporter activity & $0.10 \%$ \\
\hline Auxin efflux transmembrane transporter activity & $0.10 \%$ \\
\hline Outward rectifier potassium channel activity & $0.10 \%$ \\
\hline Ion transmembrane transporter activity & $0.10 \%$ \\
\hline Ion channel activity & $0.10 \%$ \\
\hline Channel regulator activity & $0.10 \%$ \\
\hline Inorganic anion exchanger activity & $0.10 \%$ \\
\hline Anion transmembrane transporter activity & $0.10 \%$ \\
\hline Inward rectifier potassium channel activity & $0.10 \%$ \\
\hline L-glutamate transmembrane transporter activity & $0.10 \%$ \\
\hline Zinc ion transmembrane transporter activity & $0.10 \%$ \\
\hline Porin activity & $0.10 \%$ \\
\hline
\end{tabular}

The most abundant molecular function categories were binding activity (39\%) and catalytic activity (67\%). Binding activity included copper, zinc, calcium, manganese, cobalt and ferritin binding indicating that excess boron alters signal transduction and vesicle trafficking in the cell. Catalytic activities of enzymes such as serine/threonine kinase, GTPase, ATPase, $\mathrm{H}^{+}$transporting ATP synthase, and oxidoreductase were regulated under boron stress. Differentially expressed transporters included proton, glucose, malate, inorganic phosphate, L-ascorbic acid, L-glutamate, auxin, and ion transporters. Transporters for minerals including calcium, sulfate, and manganese were also identified in this category. Moreover, three previously identified boron transporters were found: A. thaliana BOR6 putative boron transporter protein (Transcript Name: TRINITY_DN188130_c0_g1_i1:01084), A. thaliana TIP1-3 protein (Transcript Name: TRINITY_DN222891_c3_g1_i1:0-216), and O. sativa NIP protein (Transcript Name: TRINITY_DN210823_c0_g3_i1:4-269). 
Annotated transcripts were uploaded to the KEGG system for metabolic pathway analysis (Kanehisa, 2002). A total of 756 proteins were found to have interactions with pathways in the KEGG database (Suppl. Table 6). In this database, 327 (43.25\%) proteins fell into the general metabolism category. Of these metabolism-related proteins, 66 were involved in carbon metabolism, 64 in energy metabolism, 50 in amino acid metabolism, 31 in nucleic acid metabolism, 24 in lipid metabolism and 7 in secondary metabolism. The remaining 34 proteins were placed in other metabolism-related subcategories. A total of 387 proteins (51.2 $\%$ ) were in the genetic information process category. Of these, the most proteins (184) fell into the translation subcategory. The protein folding category was the second most populous group in genetic information processes with 98 proteins. Environmental information processes were also observed for 152 proteins $(20.1 \%)$ with 148 proteins matching signal transduction and four matching membrane transport. Finally, 152 proteins $(20.1 \%)$ were associated with cellular processes. In this category, two subgroups resulted in high protein matches: 86 proteins in the cellular growth and death subcategory and 42 proteins in the transport and catabolism subcategory.

\subsection{Evolutionary relationships among transporters}

$O$. sativa and A. thaliana are not boron hyperaccumulating plants; therefore, boron transporters in $P$. distans may have been annotated to other ion transporters in these species. Phylogenetic analysis was used to determine the degree of evolutionary similarity between known boron transporters (from O. sativa, A. thaliana, B. napus, and H. vulgare) and the annotated A. thaliana and O. sativa boron (BOR6), aquaporin (NIP and TIP), sugar, sulfate, anion, inorganic phosphate, and $\mathrm{ABC}$ transporters from our dataset (Figure 2). A total of 28 amino acid sequences were compared over 160 positions. The samples included an $A$. thaliana nuclear transport factor protein as outgroup. The phylogenetic analysis indicated that the identified sugar, sulfate, anion, inorganic phosphate and $A B C$ transporter proteins were distinct from boron transporters which were also distinct from aquaporins. The mean pdistance was $30 \%$ between boron transporters and $60 \%$ between aquaporins. 


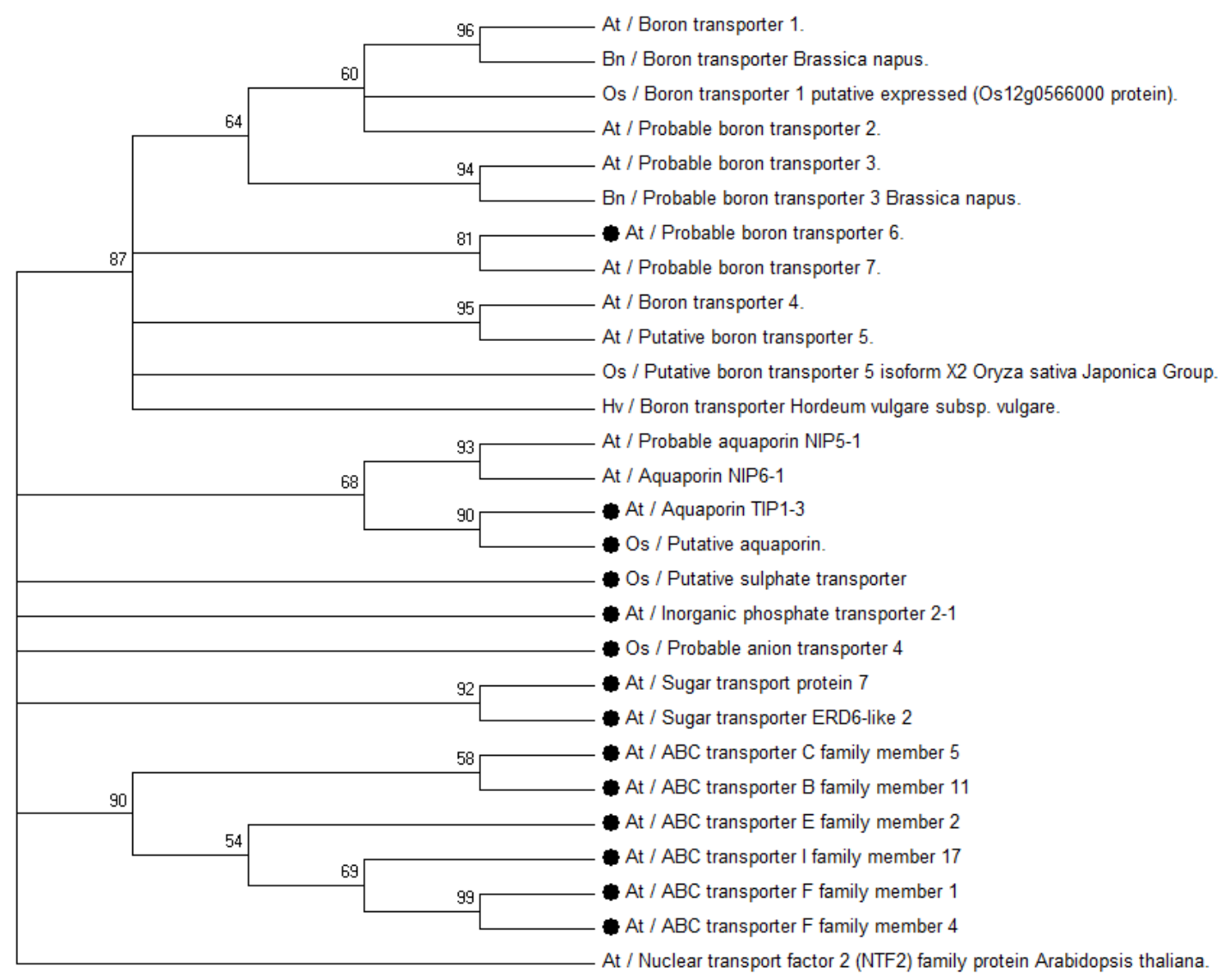

Figure 2: Maximum Likelihood phylogenetic tree representing the evolutionary relationship of boron TIP and NIP transporters and other ion and molecule transporters of several species. A. thaliana NTF2 is used as outgroup. The evolutionary history was inferred using the maximum likelihood method based on the Le Gascuel 2008 model. The tree with the highest log likelihood $(-8734,1061)$ is shown. Bootstrap values are indicated at the branches. There were a total of 160 positions in the final dataset. indicates the annotated transcripts from this study.

\subsection{Real-time PCR results of annotated transcripts}

A total of 32 transcripts were selected for verification of their expression levels using quantitative-PCR (q-PCR). Transcripts were chosen randomly based on their differential expression between control and stress samples. The q-PCR analysis was performed according to the $2^{-\Delta \Delta \mathrm{Ct}}$ method. Up and down-regulated transcripts are shown in Figure 3. The most significant five up-regulated transcripts were annotated to: an aquaporin of $O$. sativa (DN210823); a photosystem II protein in Arabidopsis (DN192927); a 4-hydroxy-4-methyl-2oxoglutarate aldolase in A. thaliana (DN220021); a ferric reduction oxidase in A. thaliana (DN224067); and FRIGIDA, which is required for FLC (Flowering Locus C) activity in A. thaliana (DN111068)(Figure 3A). Significant down-regulation was observed for four transcripts: three of which were annotated to have oxidoreductase activities in O. sativa 
(DN212455, DN205322, DN216505) and one that was annotated to aquaporin TIP1-3 in $A$. thaliana (DN222891)(Figure 3B and Suppl. Table 7).

A.

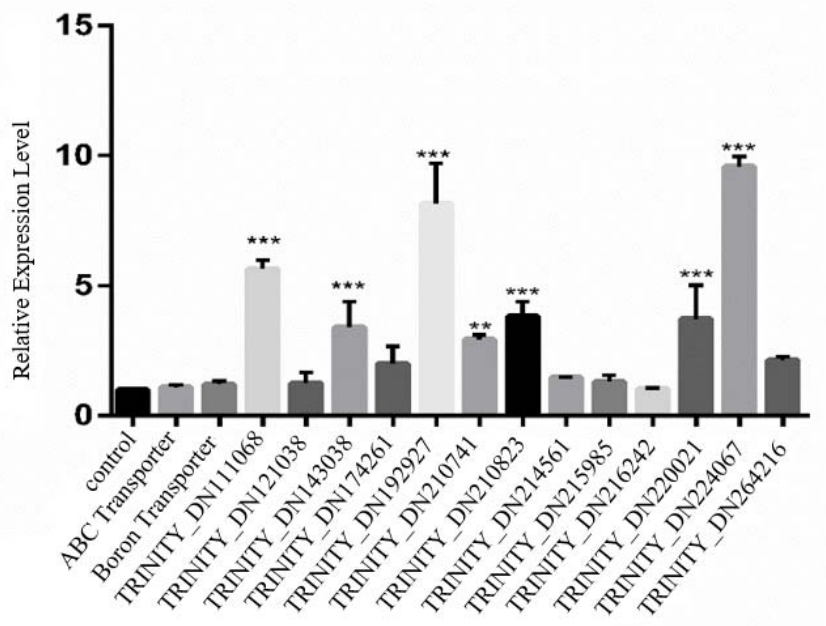

B.

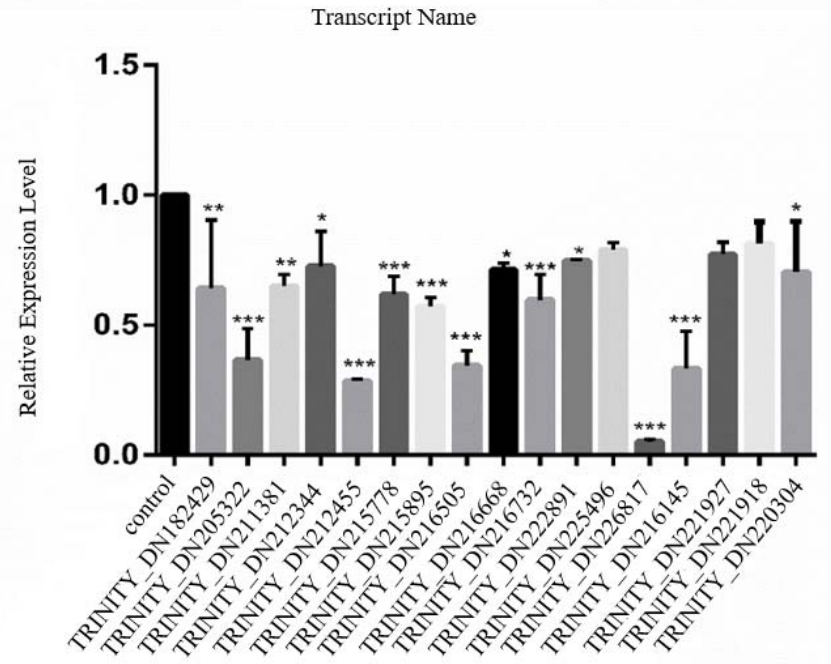

Figure 3: Real-time PCR results of $P$. distans transcriptome for 32 selected transcripts. (A) Fifteen of the transcripts were confirmed to be up-regulated; while 17 were confirmed to be down-regulated (B). Actin was used as internal control and error bars indicate standard deviation of three technical repeats. *** indicates significant difference at $\mathrm{p} \leq 0.001$, ** indicates significant difference at $\mathrm{p} \leq 0.01$ and $*$ indicates significant difference at $\mathrm{p} \leq 0.05$ with respect to control.

\section{Discussion}

Phytoremediation and phytoextraction are clean, simple, cost-effective, environmentally friendly methods for removing toxic elements from soil (Rámilaa et al., 2015). These methods rely on plants such as $P$. distans, an extreme hyperaccumulator of boron. Elucidation of the mechanism(s) by which $P$. distans accumulates and tolerates normally toxic levels of boron may allow development of a faster growing, higher biomass boron hyperaccumulator. This study provides the first broad examination of $P$. distans' transcriptomic response to boron 
hyperaccumulation. According to the analysis of RNA-Seq data generated in this study, 3312 differentially expressed transcripts were identified and 1652 of them were annotated to 1107 unique proteins with homologs in A. thaliana and $O$. sativa. In contrast, 1660 transcripts had no homologs in $A$. thaliana or $O$. sativa. Thus, these transcripts may be specific to $P$. distans and some may play roles in boron hyperaccumulation, a mechanism which is not present in $A$. thaliana and $O$. sativa.

Plants activate functional and regulatory genes to avoid or tolerate disruptive situations that accompany environmental stresses such as drought, cold, salinity and metalloid accumulation (Shinozaki et al., 2003, Shinozaki and Yamaguchi-Shinozaki, 2007). Many of these genes play roles in basic plant metabolism and are not specific to the stress response. Therefore, this discussion will only focus on stress-related proteins and plant hormones that are differentially regulated under excess boron.

\section{Stress-related molecules}

Stress-related molecules are known to have roles in the plant's response to a wide variety of biotic and abiotic conditions (Kobayashi et al., 2014). According to KEGG analysis, certain stress-related molecules were highly active under excess boron as compared to normal boron levels. For example, the A. thaliana homolog of UDP-glycosyltransferase (UniProtID: U88A1_ARATH; Transcript Name: TRINITY_DN223147_c5_g2_i1:16-443), which plays a role in flavonoid biosynthesis, was highly up-regulated (Suppl. Table 7). Flavonoids are wellknown antioxidants and are important in detoxifying the excess free radicals that plants produce under stress.

Another pathway that was affected by high boron stress was the malate pathway. Activation of this pathway is correlated with abiotic stress (Kumar et al., 2000). Four malaterelated A. thaliana homolog proteins (UniProtIDs: B3H477_ARATH, FUM1_ARATH, FUM2_ARATH, and MAOP3_ARATH) were down-regulated under excess boron. In contrast, malate dehydrogenase 1 enzyme, which is responsible for converting malate to oxaloacetate, was up-regulated (UniProtID: MDHC1_ARATH) (Suppl. Table 7). This combined increase in malate dehydrogenase 1 and decreased expression of two fumarate hydratases (UniProtIDs: FUM1-2 and B3H477) under boron stress indicates altered regulation in the glyoxylate pathway at malate (Figure 4A) which is in line with previous findings (Beevers et al., 2014). In this pathway, isocitrate is converted to malate via the intermediate molecule, glyoxylate. Glyoxylate and pyruvate can also be formed by a low affinity reaction catalyzed by 4-hydroxy-4-methyl-2-oxoglutarate aldolase (Figure 4B) (Maruyama, 1990). In 
boron-stressed plants, two 4-hydroxy-4-methyl-2-oxoglutarate aldolases (RRAA2_ARATH and RRAA3_ARATH) were significantly up-regulated (FPKMs: 426.28 and 253.61, respectively) (Suppl. Table 7). Thus, high activity of these aldolases can result in increased glyoxylate which is then converted to malate. Malate can then be transported out of the cell with ions like $\mathrm{K}+$ in order to balance cellular $\mathrm{pH}$, a mechanism that is known to be a response to aluminum tolerance in wheat (Ryan et al., 1995). Thus, these results indicate that malate and related proteins have critical roles in boron hyperaccumulation.

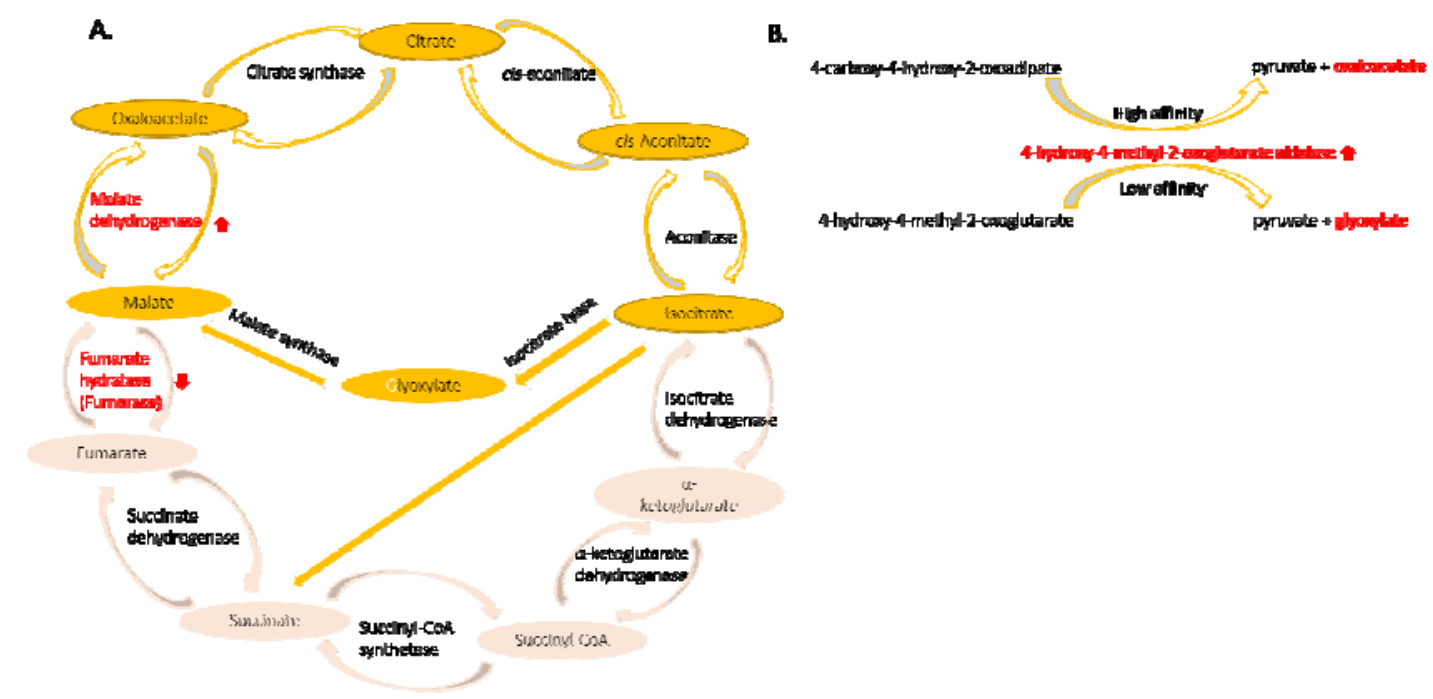

Figure 4: A) The glyoxalate pathway and B) 4-hydroxy-4-methyl-2-oxoglutarate aldolase reactions. Molecules in red font were affected by boron stress.

Plant cells are enclosed within cell walls which form physical barriers and provide tolerance to turgor pressure (Baskin, 2005). The cell wall consists of polysaccharides, proteins and phenolic compounds (Levy and Staehelin, 1992). Boron is another important structural component of the cell wall as it crosslinks rhamnogalacturonan-II molecules, thereby providing stability. Expansin proteins are also found in the wall and are responsible for cell enlargement by loosening the wall (Cosgrove, 2005). Expansins directly interact with RD22 proteins to mediate cell enlargement (Wang et al., 2012). RD22 proteins contain a BURP domain, an amino acid sequences which is highly conserved in plant species (Xu et al., 2010). As an acronym, BURP comes from: BNM2 (Brassica napus microspore-derived embryos protein) (Treacy et al., 1997), USP (Vicia faba; unidentified seed protein) (Bassüner et al., 1988), RD22 (A. thaliana protein responsive to desiccation) (Yamaguchi-Shinozaki, K. Shinozaki, 1993), and PG1 $\beta$ (Solanum lycopersicum $\beta$ subunit of polygalacturonase isozyme 1) (Zheng et al., 1992). Here we detected, the upregulation of the A. thaliana homolog of the RD22 protein (Table 3). In addition to its role in cell enlargement, RD22 was reported to be 
responsible for increased levels of lignin precursor in cell walls under salt stress (Wang et al., 2012). Under high boron, the excess boron has been shown to interact with lignin precursors in Pinus radiata organ cultures (Reid, 2007). Therefore, the up-regulated RD22 homolog in $P$. distans may provide additional lignin precursors, thereby increasing the boron binding capacity of cell walls under stress. Thus, RD22 may be an important component of the hyperaccumulation mechanism in $P$. distans.

\section{Transporter proteins}

The first identified boron tolerance-related gene was Bot 1 which expresses a putative transmembrane B efflux transporter in barley (Reid, 2007). Many studies on boron efflux transporters showed that the presence of these transporters is controlled by cellular boron concentration. Miwa et al. (2007) observed that under low boron concentrations, AtBOR1 facilitates boron uptake from roots to shoots; while under high boron, AtBOR1 undergoes endocytosis (Miwa et al., 2007; Miwa et al., 2006). These findings indicate that boron concentration affects the dynamics of transporter proteins. A possible explanation is that boron itself interacts with the ribose in mRNA and changes its stability thereby affecting transcription and translation (Pommerrenig, Diehn, \& Bienert, 2015). In our study, the $A$. thaliana BOR6 homolog (UniProtID: BOR6_ARATH), a transporter for boron efflux, was up-regulated in $P$. distans (Suppl. Table 7). Since $P$. distans is a hyperaccumulator plant, potential roles of this boron transporter in the cell are: $i$ ) facilitation of boron transport from root to shoot and ii) transport of boron from the cell into the cell wall.

Major intrinsic proteins (MIPs), also known as aquaporin proteins, facilitate the transport of water across biological membranes and are permeable to other small, uncharged molecules such as glycerol, solutes and ions (Quigley et al., 2002; Tyerman et al., 2002;

Aharon et al., 2003; Pommerrenig et al., 2015). MIPs are categorized into seven subgroups in the plant kingdom including NOD26-like intrinsic proteins (NIPs) and tonoplast intrinsic proteins (TIPs) transporters (Afzal et al., 2016; Pérez Di Giorgio et al., 2016). NIPs are generally located in the plasma membrane and endoplasmic reticulum; TIPs are localized in the vacuole membrane (tonoplast) and thylakoid inner membrane (Afzal et al., 2016). NIPs are the most divergent plant MIP subfamily with respect to their substrate specificities and amino acid sequences. The NIP aquaporin family is unique to plants and NIPs are selectively permeable to metalloids (Pommerrenig et al., 2015). Specifically, NIP II and NIP III actively transport boron. In our study two types of aquaporins were identified, one of them was a homolog of an O. sativa NIP (UniProtID: Q949A7_ORYSA; Transcript Name: TRINITY_DN210823_c0_g3_i1:4-269) and the other was a homolog of an A. thaliana TIP 
(UniProtID: TIP13_ARATH; Transcript Name: TRINITY_DN222891_c3_g1_i1:0-216)

(Suppl. Table 7). The $O$. sativa homolog NIP-type aquaporin was up-regulated in $P$. distans under boron stress. Overexpression of an aquaporin could cause tolerance to distinct stress conditions. For example, PgTIPl was overexpressed in A. thaliana and plants showed increased tolerance to salt and drought stress but decreased tolerance to cold(Peng et al., 2007). Therefore, our results suggest that the $O$. sativa NIP aquaporin is responsible for cellular boron uptake in $P$. distans. On the other hand, the A. thaliana TIP homolog was down-regulated indicating that not all aquaporins are involved in boron transport and/or that the vacuole is not an important storage site for boron.

$\mathrm{ABC}$ transporters are members of a diverse family. Their susbtrate specificities vary from carbohydrates to ions and some of them are completely specialized to transport ions and solutes. For example, mntABCD is a $\mathrm{ABC}$ transporter and selectively permeable for manganese (Baumgart \& Frunzke, 2015). In our study, five different A. thaliana ABC transporters (ABC-B, C, E, F, I) were differentially expressed under boron stress. All of the ABC transporters were up-regulated with the exception of AB17I_ARATH. The activation of this transporter group may be due to the fact that: $i$ ) ABC transporters are permeable to a wide variety substrates and some of them may be able to transport boron and ii) they can transport boron-binding molecules such as sorbitol. Thus, ABC transporters may be a significant component of the boron hyperaccumulation mechanism in $P$. distans.

Under excess boron, a sulfate transporter was down-regulated in $P$. distans (UniProtID: Q8S317_ORYSA). Sulfate transport mechanisms are divided into four groups. The first is sulfate co-transport with a proton, the second is co-transport with sodium $(\mathrm{Na})$, and the third is sulfate antiport with an anion. The fourth mechanism is ATP-dependent ABC transporter-mediated sulfate uptake (Sze et al., 2012). Sulfate transporters play important roles in response to metal stresses in a metal-specific manner (Kumar et al., 2011). Sulfate transporters are responsible for transport of some oxyanions, such as molybdate and chromate (Appenrothaet al., 2008; Fitzpatrick et al., 2008; Kumar et al., 2011). Kumar et al. (2011) observed that seven sulfate transporters were up-regulated by arsenate and cadmium, ten were up-regulated by chromium and five by lead exposure. However, our study indicated downregulation of a sulfate transporter in response to boron hyperaccumulation. Because excess boric acid will acidify the cellular environment, less proton pumping is required to maintain cellular $\mathrm{pH}$.

Depending on plant type, sugars (such as sucrose), sugar alcohols (such as mannitol) and amino acids (such as glycine) accumulate under stress conditions and these help plants 
cope with stress (Taji et al., 2002; Bartels and Sunkar, 2005). Sugar alcohols provide protection from stress by scavenging hydroxyl radicals and/or stabilizing macromolecular structure (Seki et al., 2007). Inositol is a sugar alcohol which also has a role in the biogenesis of the uronosyl and pentosyl units of pectin, hemicelluloses, and related structures in plant cell walls (Loewus and Loewus, 1983; Loewusa and Murthy, 2000). An inositol transporter was up-regulated in $P$. distans (UniProtID: INT2_ARATH; Transcript name: TRINITY_DN172179_c0_g2_i1:0-695,2.5518) under high boron. An increased level of this transporter could be used in the cell to increase the level of inositol available to scavenge reactive oxygen species and/or chelating boron, thereby protecting the cell. Increased cellular inositol may also be required for the synthesis of cell wall pectin and its precursor to bind to the increased amount of boron in the cell wall. The similarity between the inositol and boron transporters of A. thaliana (Tanaka and Fujiwara, 2008) suggests a third possibility: the inositol tranporter may also transport boron.

\section{Plant hormones}

Plant hormones play critical roles in stress conditions by providing physiological and biochemical responses to stress factors (Colebrook et al., 2014). Abscisic acid (ABA) signaling is the central regulator of the abiotic stress resistance pathway in plants (Hubbard et al., 2010). Under drought conditions, plants cope with stress by increasing the amount of ABA causing stomatal closure and reduced transpiration (Cutler et al., 2010). In our dataset, an A. thaliana homolog of ABA and related proteins such as phosphatase (UniProtID: P2C16_ARATH; Transcript Name: TRINITY_DN220107_c1_g6_i1:12-396) was downregulated (Suppl. Table 7). The absence of ABA is associated with increases in cytosolic free calcium (Allen et al., 1999), calcium-dependent proteins (Mustilli et al., 2002) and reactive oxygen species (Murata et al., 2001). According to our findings, calcium-dependent proteins were up-regulated under excess boron, thus, supporting the relationship between ABA and calcium-related proteins. In addition, it is well-known that both calcium and boron are important components of pectic polysaccharides in the cell wall (Matoh and Kobayashi, 1998). Therefore, an increase in boron could trigger up-regulation of calcium levels and calcium-dependent proteins in order to maintain cell wall integrity. Ethylene and ABA are antagonists: ethylene triggers catabolism of ABA (Colebrook et al., 2014). In our analysis, five ethylene response proteins had increased expression under stress (Suppl. Table 7). Thus as expected, the ethylene response was up-regulated while ABA was down-regulated under boron stress. 
Another plant hormone that has a role in stress defense is gibberellin (GA). GAs are involved in cell wall loosening in plants, thus, contributing to cell expansion (Cosgrove, 1993; Park et al., 2015). In addition, GAs play roles in plant development and growth, thus they are inhibited under stress conditions to limit growth (Yamaguchi, 2008). For example, GA was reduced under high salinity stress in A. thaliana (Magome et al., 2004). Interestingly, in our study, positive regulators of GAs (UniProtIDs: TSN1_ARATH, TSN2_ARATH; Transcript Names: TRINITY_DN151004, TRINITY_DN122991) had increased expression under boron stress (Suppl. Table 7). The excess GAs produced under stress may maintain cell wall looseness as it is known that boron toxicity is usually accompanied by increased cell wall rigidity. Thus, GAs may have a critical role in $P$. distans boron tolerance by preventing cell rigidity, thereby allowing survival and continued growth.

\section{Conclusion}

P. distans is a hyperaccumulator, monocot plant and is a non-model organism. Limited knowledge about this species and its hyperaccumulation mechanism led us to use a transcriptomics approach to elucidate stress tolerance and potential hyperaccumulation mechanisms in $P$. distans. Signaling and metabolic pathways in Puccinellia were studied under salinity, alkaline soil and chilling stress conditions (Babao $\square$ lu et al., 2004;

Padmanabhan et al., 2012; Zhao et al., 2016), therefore, we focused on stress-related molecules, transporters and plant hormones. Strong evidence was obtained that the boron tolerance and hyperaccumulation mechanism of $P$. distans involves alterations in the malate pathway, changes in cell wall components that allow sequestration of excess boron without toxic effects, and at least one putative boron transporter and two putative aquaporins. Transgenic overexpression of this boron transporter and aquaporins in P. distans or determination of their subcellular localization will provide deeper information about their direct role in the boron hyperaccumulation mechanism. The next step after confirmation, these genes could be transferred to economically important plants to gain boron tolerance. These results provide new information and insights into the underlying boron stress responsive mechanism in shoots and they are applicaple for agronomy. Additionally, using Puccinellia, itself for phytoremediation and/or phytoextraction will provide new and economical step to remove excess boron from contaminated soil. Therefore this will be useful for soil depollution and for simple boron purification. 


\section{References:}

Afzal, Z., Howton, T., Sun, Y., \& Mukhtar, M. (2016). The Roles of Aquaporins in Plant Stress Responses. Journal of Developmental Biology, 4(1), 9. http://doi.org/10.3390/jdb4010009

Aharon, R., Shahak, Y., Wininger, S., Bendov, R., Kapulnik, Y., \& Galili, G. (2003). Overexpression of a plasma membrane aquaporin in transgenic tobacco improves plant vigor under favorable growth conditions but not under drought or salt stress. The Plant Cell, 15(February), 439-447. http://doi.org/10.1105/tpc.009225

Allen, G. J., Kuchitsu, K., Chu, S. P., Murata, Y., \& Schroeder, J. I. (1999). Arabidopsis abi11 and abi2-1 phosphatase mutations reduce abscisic acid-induced cytoplasmic calcium rises in guard cells. The Plant Cell, 11(9), 1785-98.

Appenrotha, K.-J., Luthera, A., Jetschkeb, G., \& Gabrys, H. (2008). Modification of chromate toxicity by sulphate in duckweeds (Lemnaceae). Aquatic Toxicology, 89(3), 167-171. http://doi.org/10.1016/j.aquatox.2008.06.012

Babao $\square$ lu, M., Gezgin, S., Topal, A., Sade, B., \& Dural, H. (2004). Gypsophila sphaerocephala Fenzl ex Tchihat.: A boron hyperaccumulator plant species that may phytoremediate soils with toxic B levels. Turkish Journal of Botany, 28(3), 273-278.

Bar, C. (2015). Elucidation of boron hyperaccumulation and tolerance mechanisms in puccinellia distans ( jacq .) Parl. Using proteomics approach. Izmir Institute of Technology.

Bartels, D., \& Sunkar, R. (2005). Drought and Salt Tolerance in Plants. Critical Reviews in Plant Sciences, 24(1), 23-58. http://doi.org/10.1080/07352680590910410

Baskin, T. I. (2005). Anisotropic Expansion Of The Plant Cell Wall. Annual Review of Cell and Developmental Biology, 21(1), 203-222. http://doi.org/10.1146/annurev.cellbio.20.082503.103053

Bassüner, R., Bäumlein, H., Huth, A., Jung, R., Wobus, U., Rapoport, T. A., Saalbach, G., Müntz, K. (1988). Abundant embryonic mRNA in field bean (Vicia faba L.) codes for a new class of seed proteins: cDNA cloning and characterization of the primary translation product. Plant Molecular Biology, 11(3), 321-334.

Baumgart, M., \& Frunzke, J. (2015). The manganese-responsive regulator MntR represses transcription of a predicted ZIP family metal ion transporter in Corynebacterium glutamicum. FEMS Microbiology Letters, 362(1). http://doi.org/10.1093/femsle/fnu001

Beevers, D. G., Lip, G. Y., \& O’Brien, E. T. (2014). ABC of Hypertension. John Wiley \& Sons.

Binns, D., Dimmer, E., Huntley, R., Barrell, D., O’Donovan, C., \& Apweiler, R. (2009). QuickGO: a web-based tool for Gene Ontology searching. Bioinformatics, 25(22), 30453046. http://doi.org/10.1093/bioinformatics/btp536

BOREN. (2012). BOREN. Retrieved from http://www.boren.gov.tr/en/boron/reserves

Camacho-Cristóbal, J. J., Herrera-Rodríguez, M. B., Beato, V. M., Rexach, J., NavarroGochicoa, M. T., Maldonado, J. M., \& González-Fontes, A. (2008). The expression of 
several cell wall-related genes in Arabidopsis roots is down-regulated under boron deficiency. Environmental and Experimental Botany, 63(1-3), 351-358.

http://doi.org/10.1016/j.envexpbot.2007.12.004

Chaumont, F., Moshelion, M., \& Daniels, M. J. (2005). Regulation of plant aquaporin activity. Biology of the Cell, 97(10), 749-764.

Colebrook, E. H., Thomas, S. G., Phillips, A. L., \& Hedden, P. (2014). The role of gibberellin signalling in plant responses to abiotic stress. Journal of Experimental Biology, 217(1), 67-75. http://doi.org/10.1242/jeb.089938

Conesa, A., Götz, S., García-Gómez, J. M., Terol, J., Talón, M., \& Robles, M. (2005). Blast2GO: A universal tool for annotation, visualization and analysis in functional genomics research. Bioinformatics, 21(18), 3674-3676. http://doi.org/10.1093/bioinformatics/bti610

Cosgrove, D. J. (1993). Water Uptake by Growing Cells: An Assessment of the Controlling Roles of Wall Relaxation, Solute Uptake, and Hydraulic Conductance. International Journal of Plant Sciences, 154(1), 10-21. http://doi.org/10.1086/297087

Cosgrove, D. J. (2005). Growth of the plant cell wall. Nature Reviews Molecular Cell Biology, 6(11), 850-861. http://doi.org/10.1038/nrm1746

Cutler, S. R., Rodriguez, P. L., Finkelstein, R. R., \& Abrams, S. R. (2010). Abscisic acid: emergence of a core signaling network. Annual Review of Plant Biology, 61(1), 651-679. http://doi.org/10.1146/annurev-arplant-042809-112122

Dannel, F., Pfeffer, H., \& Römheld, V. (2000). Characterization of root boron pools, boron uptake and boron translocation in sunflower using the stable isotopes 10B and 11B. Australian Journal of Plant Physiology, 27(330), 397-405. http://doi.org/http://dx.doi.org/10.1071/PP99086

Dordas, C., Chrispeels, M. J., \& Brown, P. H. (2000). Permeability and channel-mediated transport of boric acid across membrane vesicles isolated from squash roots. Plant Physiology, 124(3), 1349-62. http://doi.org/10.1104/pp.124.3.1349

Fitzpatrick, K. L., Tyerman, S. D., \& Kaiser, B. N. (2008). Molybdate transport through the plant sulfate transporter SHST1. FEBS Letters, 582(10), 1508-1513. http://doi.org/10.1016/j.febslet.2008.03.045

Goff, L., Trapnell, C., \& Kelley, D. R. (2013). cummeRbund: Analysis, Exploration, Manipulation, and Visualization of Cufflinks High-throughput Sequencing Data.

Goldbach, H. E., Yu, Q., Wingender, R., Schulz, M., Wimmer, M., Findeklee, P., \& Baluska, F. (2001). Rapid response reactions of roots to boron deprivation. Journal of Plant Nutrition and Soil Science, 164(2), 173-181.

GOLDBACH H. E. (1997). A critical review on current hypotheses concerning the role of boron in higher plants $\square$ : suggestions for further research and methodological requirements. Journal of Trace and Microprobe Techniques, 15(1), 51-91.

Haas, B. J., Papanicolaou, A., Yassour, M., Grabherr, M., Blood, P. D., Bowden, J., Couger, M. B., Eccles, D., Li, B., Lieber, M., MacManes, M. D., Ott, M., Orvis, J., Pochet, N., Strozzi, F., Weeks, N., Westerman, R., William, T., Dewey, C. N., Henschel, R., LeDuc, 
R. D., Friedman, N., Regev, A. (2013). De novo transcript sequence reconstruction from RNA-seq using the Trinity platform for reference generation and analysis. Nature Protocols, 8(8), 1494-1512. http://doi.org/10.1038/nprot.2013.084

Hanaoka, H., Uraguchi, S., Takano, J., Tanaka, M., \& Fujiwara, T. (2014). OsNIP3;1, a rice boric acid channel, regulates boron distribution and is essential for growth under borondeficient conditions. The Plant Journal, 78(5), 890-902. http://doi.org/10.1111/tpj.12511

Hayes, J. E. (2004). Boron Tolerance in Barley Is Mediated by Efflux of Boron from the Roots. Plant Physiology, 136(2), 3376-3382. http://doi.org/10.1104/pp.103.037028

Hoagland, D. R., \& Arnon, D. I. (1950). The water-culture method for growing plants without soil. California Agricultural Experiment Station, 347, 32.

Hubbard, K. E., Nishimura, N., Hitomi, K., Getzoff, E. D., \& Schroeder, J. I. (2010). Early abscisic acid signal transduction mechanisms: newly discovered components and newly emerging questions. Genes \& Development, 24(16), 1695-1708. http://doi.org/10.1101/gad.1953910

Jamjod, S. (1996). Genetics of boron tolerance in durum wheat. The University of Adelaide.

Jenkin, M. J. (1993). Genetics of boron tolerance in barley. University of Adelaide.

Kanehisa, M. (2002). he KEGG database. silico simulation of biological processes.

Kirk, G. J., \& Loneragan, J. F. (1988). Functional Boron Requirement for Leaf Expansion and Its Use as a Critical Value for Diagnosis of Boron Deficiency in Soybean. Agronomy Journal, 80(5), 758. http://doi.org/10.2134/agronj1988.00021962008000050013x

Kobayashi, S., Satone, H., Tan, E., Kurokochi, H., Asakawa, S., Liu, S., \& Takano, T. (2014). Transcriptional Responses of a Bicarbonate-Tolerant Monocot, Puccinellia tenuiflora, and a Related Bicarbonate-Sensitive Species, Poa annua, to NaHCO3 Stress.

International Journal of Molecular Sciences, 16(1), 496-509. http://doi.org/10.3390/ijms16010496

Kumar, S., Asif, M. H., Chakrabarty, D., Tripathi, R. D., \& Trivedi, P. K. (2011). Differential expression and alternative splicing of rice sulphate transporter family members regulate sulphur status during plant growth, development and stress conditions. Functional \& Integrative Genomics, 11(2), 259-273. http://doi.org/10.1007/s10142-010-0207-y

Kumar, Shah, \& Dubey. (2000). Salinity induced behavioural changes in malate dehydrogenase and glutamate dehydrogenase activities in rice seedlings of differing salt tolerance. Plant Science $\square$ : An International Journal of Experimental Plant Biology, 156(1), 23-34.

Langmead, B., \& Salzberg, S. L. (2012). Fast gapped-read alignment with Bowtie 2. Nature Methods, 9(4), 357-359. http://doi.org/10.1038/nmeth.1923

Larkin, M. A., Blackshields, G., Brown, N. P., Chenna, R., Mcgettigan, P. A., McWilliam, H., Valentin, F., Wallace, I. M., Wilm, A., Lopez, R., Thompson, J. D., Gibson, T. J., Higgins, D. G. (2007). Clustal W and Clustal X version 2.0. Bioinformatics, 23(21), 2947-2948. http://doi.org/10.1093/bioinformatics/btm404

Le, S. Q., \& Gascuel, O. (2008). An Improved General Amino Acid Replacement Matrix. 
Molecular Biology and Evolution, 25(7), 1307-1320.

http://doi.org/10.1093/molbev/msn067

Levy, S., \& Staehelin, L. A. (1992). Synthesis, assembly and function of plant cell wall macromolecules. Current Opinion in Cell Biology, 4(5), 856-862. http://doi.org/10.1016/0955-0674(92)90111-O

Loewus, F. A., \& Loewus, M. W. (1983). myo-INOSITOL: ITS BIOSYNTHESIS AND METABOLISM. Ann. Rev. Plant Physiol, 34(137), 61.

Loewusa, F. A., \& Murthy, P. P. N. (2000). myo-Inositol metabolism in plants. Plant Science, $150(1), 1-19$.

Magome, H., Yamaguchi, S., Hanada, A., Kamiya, Y., \& Oda, K. (2004). dwarf and delayedflowering 1, a novel Arabidopsis mutant deficient in gibberellin biosynthesis because of overexpression of a putative AP2 transcription factor. The Plant Journal $\square$ : For Cell and Molecular Biology, 37(5), 720-9.

Marschner, H. (2011). Marschner's mineral nutrition of higher plants. Academic press.

Marschner, H., \& Marschner, P. (2012). Marschner's Mineral Nutrition of Higher Plants. Elsevier. http://doi.org/10.1016/B978-0-12-384905-2.00021-2

Martin, M. (2011). Cutadapt removes adapter sequences from high-throughput sequencing reads. EMBnet.journal, 17(1), 10. http://doi.org/10.14806/ej.17.1.200

Maruyama, K. (1990). Purification and properties of 4-hydroxy-4-methyl-2-oxoglutarate aldolase from Pseudomonas ochraceae grown on phthalate. Journal of Biochemistry, $108(2), 327-33$.

Matoh, T. (2001). Boron in plant nutrition and cell wall development. In N. Ae, J. Arihara, K. Okada, \& A. Srinivasan (Eds.), Plant Nutrient Acquisition (pp. 227-250). Tokyo: Springer Japan. http://doi.org/10.1007/978-4-431-66902-9

Matoh, T., \& Kobayashi, M. (1998). Boron and calcium, essential inorganic constituents of pectic polysaccharides in higher plant cell walls. Journal of Plant Research, 111(1), 179-190. http://doi.org/10.1007/BF02507164

Matoh, T., \& Ochiai, K. (2005). Distribution and Partitioning of Newly Taken-up Boron in Sunflower. Plant and Soil, 278(1-2), 351-360. http://doi.org/10.1007/s11104-005-03722

Mi, H., Huang, X., Muruganujan, A., Tang, H., Mills, C., Kang, D., \& Thomas, P. D. (2016). PANTHER version 11: expanded annotation data from Gene Ontology and Reactome pathways, and data analysis tool enhancements. Nucleic Acids Research, 1-15. http://doi.org/10.1093/nar/gkw1138

Miwa, K., Takano, J., \& Fujiwara, T. (2006). Improvement of seed yields under boronlimiting conditions through overexpression of BOR1, a boron transporter for xylem loading, in Arabidopsis thaliana. The Plant Journal, 46(6), 1084-1091. http://doi.org/10.1111/j.1365-313X.2006.02763.x

Miwa, K., Takano, J., Omori, H., Seki, M., Shinozaki, K., \& Fujiwara, T. (2007). Plants tolerant of high boron levels. Science (New York, N.Y.), 318(5855), 1417. 
http://doi.org/10.1126/science.1146634

Murata, Y., Pei, Z. M., Mori, I. C., \& Schroeder, J. (2001). Abscisic acid activation of plasma membrane $\mathrm{Ca}(2+)$ channels in guard cells requires cytosolic $\mathrm{NAD}(\mathrm{P}) \mathrm{H}$ and is differentially disrupted upstream and downstream of reactive oxygen species production in abi1-1 and abi2-1 protein phosphatase 2C mutants. The Plant Cell, 13(11), 2513-23.

Mustilli, A.-C., Merlot, S., Vavasseur, A., Fenzi, F., \& Giraudat, J. (2002). Arabidopsis OST1 protein kinase mediates the regulation of stomatal aperture by abscisic acid and acts upstream of reactive oxygen species production. The Plant Cell, 14(12), 3089-99.

Nable, R. O., Bañuelos, G. S., \& Paull, J. G. (1997). Boron toxicity. Plant and Soil, 193(August), 181-198. http://doi.org/10.1104/pp.110.158832

Ozturk, M., Sakcali, S., Gucel, S., \& Tombuloglu, H. (2010). Boron and Plants. In M. Ashraf, M. Ozturk, \& M. S. A. Ahmad (Eds.), Plant Adaptation and Phytoremediation (pp. 275311). Dordrecht: Springer Netherlands. http://doi.org/10.1007/978-90-481-9370-7

Padmanabhan, P., Babao $\square$ lu, M., \& Terry, N. (2012). A comparative transcriptomic analysis of the extremely boron tolerant plant Puccinellia distans with the moderately boron tolerant Gypsophila arrostil. Plant Cell Reports, 31(8), 1407-1413. http://doi.org/10.1007/s00299-012-1256-6

Padmavathiamma, P. K., \& Li, L. Y. (2007). Phytoremediation Technology: Hyperaccumulation Metals in Plants. Water, Air, and Soil Pollution, 184(1-4), 105-126. http://doi.org/10.1007/s11270-007-9401-5

Park, J., Cui, Y., \& Kang, B.-H. (2015). AtPGL3 is an Arabidopsis BURP domain protein that is localized to the cell wall and promotes cell enlargement. Frontiers in Plant Science, 6. http://doi.org/10.3389/fpls.2015.00412

Paull, J. G., Nable, R. O., \& Rathjen, A. J. (1992). Physiological and genetic control of the tolerance of wheat to high concentrations of boron and implications for plant breeding. Plant and Soil, 146(1-2), 251-260. http://doi.org/10.1007/BF00012019

Peng, Y., LinWeiming, W., \& Arora, C. (2007). Overexpression of a Panax ginseng tonoplast aquaporin alters salt tolerance, drought tolerance and cold acclimation ability in transgenic Arabidopsis plants. Planta, 226(3), 729-740.

Pérez Di Giorgio, J. A., Barberini, M. L., Amodeo, G., \& Muschietti, J. P. (2016). Pollen aquaporins: What are they there for? Plant Signaling \& Behavior, 11(9), e1217375. http://doi.org/10.1080/15592324.2016.1217375

Pommerrenig, B., Diehn, T. A., \& Bienert, G. P. (2015). Metalloido-porins: Essentiality of Nodulin 26-like intrinsic proteins in metalloid transport. Plant Science, 238, 212-227. http://doi.org/10.1016/j.plantsci.2015.06.002

Quigley, F., Rosenberg, J. M., Shachar-Hill, Y., \& Bohnert, H. J. (2002). From genome to function: the Arabidopsis aquaporins. Genome Biology, 3(1), RESEARCH0001. http://doi.org/10.1186/gb-2001-3-1-research0001

Rámila, C. D. P., Contreras, S. A., Di Domenico, C., Molina-Montenegro, M. A., Vega, A., Handford, M., Bonilla, C. A., Pizarro, G. E. (2016). Boron stress response and accumulation potential of the extremely tolerant species Puccinellia frigida. Journal of 
Hazardous Materials, 317, 476-84. http://doi.org/10.1016/j.jhazmat.2016.05.086

Rámilaa, C. D. P., Leivaa, E. D., Bonillaa, C. A., Pasténa, P. A., \& Pizarroa, G. E. (2015). Boron accumulation in Puccinellia frigida, an extremely tolerant and promising species for boron phytoremediation. Journal of Geochemical Exploration, 150, 25-34.

Reid, R. (2007). Identification of boron transporter genes likely to be responsible for tolerance to boron toxicity in wheat and barley. Plant \& Cell Physiology, 48(12), 1673-8. http://doi.org/10.1093/pcp/pcm159

Ryan, J., \& Rashid, A. (2006). Application of Soil and Plant Analysis for Applied Research and Development in West Asia-North Africa: An International Center's Perspective. Communications in Soil Science and Plant Analysis, 37(15-20), 2185-2198.

Ryan, P., Delhaize, E., \& Randall, P. (1995). Characterisation of Al-stimulated efflux of malate from the apices of Al-tolerant wheat roots. Planta, 196(1). http://doi.org/10.1007/BF00193223

Sang, W., Huang, Z.-R., Qi, Y.-P., Yang, L.-T., Guo, P., \& Chen, L.-S. (2015). An investigation of boron-toxicity in leaves of two citrus species differing in boron-tolerance using comparative proteomics. Journal of Proteomics, 123, 128-146. http://doi.org/10.1016/j.jprot.2015.04.007

Seki, M., Umezawa, T., Urano, K., \& Shinozaki, K. (2007). Regulatory metabolic networks in drought stress responses. Current Opinion in Plant Biology, 10(3), 296-302. http://doi.org/10.1016/j.pbi.2007.04.014

Shinozaki, K., \& Yamaguchi-Shinozaki, K. (2007). Gene networks involved in drought stress response and tolerance. In Journal of Experimental Botany (Vol. 58, pp. 221-227). http://doi.org/10.1093/jxb/erl164

Stiles, A. R., Bautista, D., Atalay, E., Babaoğlu, M., \& Terry, N. (2010). Mechanisms of boron tolerance and accumulation in plants: a physiological comparison of the extremely boron-tolerant plant species, Puccinellia distans, with the moderately boron-tolerant Gypsophila arrostil. Environmental Science \& Technology, 44(18), 7089-95. http://doi.org/10.1021/es1016334

Sze, H., Chen, L. Q., \& Jez, J. M. (2012). Evolutionary relationships and functional diversity of plant sulfate transporters. Frontiers in Plant Science, 2, 63-71.

Taji, T., Ohsumi, C., Iuchi, S., Seki, M., Kasuga, M., Kobayashi, M., Yamaguchi-Shinozaki, K., Shinozaki, K. (2002). Important roles of drought- and cold-inducible genes for galactinol synthase in stress tolerance in Arabidopsis thaliana. The Plant Journal $\square:$ For Cell and Molecular Biology, 29(4), 417-26.

Takano, J., Miwa, K., \& Fujiwara, T. (2008). Boron transport mechanisms: collaboration of channels and transporters. Trends in Plant Science, 13(8), 451-457.

Takano, J., Wada, M., Ludewig, U., Schaaf, G., von Wirén, N., \& Fujiwara, T. (2006a). The Arabidopsis Major Intrinsic Protein NIP5;1 Is Essential for Efficient Boron Uptake and Plant Development under Boron Limitation. The Plant Cell, 18(6), 1498-1509. http://doi.org/10.1105/tpc.106.041640

Takano, J., Wada, M., Ludewig, U., Schaaf, G., von Wirén, N., \& Fujiwara, T. (2006b). The 
Arabidopsis Major Intrinsic Protein NIP5;1 Is Essential for Efficient Boron Uptake and Plant Development under Boron Limitation. The Plant Cell, 18(6), 1498-1509.

http://doi.org/10.1105/tpc.106.041640

Takano, J., Yamagami, M., Noguchi, K., Hayashi, H., \& Fujiwara, T. (2001). Preferential translocation of boron to young leaves in Arabidopsis thaliana Regulated by the BOR1 Gene. Soil Science and Plant Nutrition, 47(2), 345-357. http://doi.org/10.1080/00380768.2001.10408398

Tamura, K., Stecher, G., Peterson, D., Filipski, A., \& Kumar, S. (2013). MEGA6: Molecular Evolutionary Genetics Analysis version 6.0. Molecular Biology and Evolution, 30(12), 2725-9. http://doi.org/10.1093/molbev/mst197

Tanabe, M., \& Kanehisa, M. (2012). Using the KEGG database resource. Current Protocols in Bioinformatics, (SUPPL.38). http://doi.org/10.1002/0471250953.bi0112s38

Tanaka, M., \& Fujiwara, T. (2008). Physiological roles and transport mechanisms of boron: Perspectives from plants. Pflugers Archiv European Journal of Physiology, 456(4), 671677. http://doi.org/10.1007/s00424-007-0370-8

Trapnell, C., Roberts, A., Goff, L., Pertea, G., Kim, D., Kelley, D. R., Pimentel, H., Salzberg, S. L., Rinn, J. L., Pachter, L. (2012). Differential gene and transcript expression analysis of RNA-seq experiments with TopHat and Cufflinks. Nature Protocols, 7(3), 562-578. http://doi.org/10.1038/nprot.2012.016

Treacy, B. K., Hattori, J., Prud'homme, I., Barbour, E., Boutilier, K., Baszczynski, C. L., Huang, B., Johnson, D. A., Miki, B. L. (1997). Bnm1, a Brassica pollen-specific gene. Plant Molecular Biology, 34(4), 603-611.

Tyerman, S. D., Niemietz, C. M., \& Bramley, H. (2002). Plant aquaporins: multifunctional water and solute channels with expanding roles. Plant, Cell \& Environment, 25(2), 173194.

Uraguchi, S., \& Fujiwara, T. (2011). Significant contribution of boron stored in seeds to initial growth of rice seedlings. Plant and Soil, 340(1-2), 435-442.

http://doi.org/10.1007/s11104-010-0614-9

Wang, H., Zhou, L., Fu, Y., Cheung, M., Wong, F., Phang, T., Sun, Z., Lam, H. (2012). Expression of an apoplast-localized BURP-domain protein from soybean ( GmRD22) enhances tolerance towards abiotic stress. Plant, Cell \& Environment, 35(11), 19321947. http://doi.org/10.1111/j.1365-3040.2012.02526.x

Wang, Y., Yang, C., Liu, G., \& Jiang, J. (2007). Development of a cDNA microarray to identify gene expression of Puccinellia tenuiflora under saline-alkali stress. Plant Physiology and Biochemistry, 45(8), 567-576. http://doi.org/10.1016/j.plaphy.2007.05.006

Xu, H., Li, Y., Yan, Y., Wang, K., Gao, Y., \& Hu, Y. (2010). Genome-scale identification of soybean BURP domain-containing genes and their expression under stress treatments. BMC Plant Biology, 10(1), 1.

Yamagishi, M., \& Yamamoto, Y. (1994). Effects of boron on nodule development and symbiotic nitrogen fixation in soybean plants. Soil Science and Plant Nutrition, 40(2), 265-274. http://doi.org/10.1080/00380768.1994.10413300 
Yamaguchi-Shinozaki, K. Shinozaki, K. (1993). The plant hormone abscisic acid mediates the drought-induced expression but not the seed-specific expression of rd22, a gene responsive to dehydration stress in Arabidopsis thaliana. Molecular and General Genetics MGG, 238(1-2), 17-25.

Yamaguchi, S. (2008). Gibberellin Metabolism and its Regulation. Annual Review of Plant Biology, 59(1), 225-251. http://doi.org/10.1146/annurev.arplant.59.032607.092804

Yau, S. K., Nachit, M. M., Ryan, J., \& Hamblin, J. (1995). Phenotypic variation in borontoxicity tolerance at seedling stage in durum wheat (Triticum durum). Euphytica, 83(3), 185-191. http://doi.org/10.1007/BF01678128

Zhao, Q., Suo, J., Chen, S., Jin, Y., Ma, X., Yin, Z., Zhang, Y., Wang, T., Luo, J., Jin, W., Zhang, X., Zhou, Z., Dai, S. (2016). Na2CO3-responsive mechanisms in halophyte Puccinellia tenuiflora roots revealed by physiological and proteomic analyses. Scientific Reports, 6(May), 32717. http://doi.org/10.1038/srep32717

Zheng, L. (1992). The [beta] Subunit of Tomato Fruit Polygalacturonase Isoenzyme 1: Isolation, Characterization, and Identification of Unique Structural Features. The Plant Cell, 4(9), 1147-1156. http://doi.org/10.1105/tpc.4.9.1147 